\title{
Drying kinetics, texture, color, and determination of effective diffusivities during sun drying of chempedak
}

\begin{abstract}
Sun drying of chempedak (Artocarpus integer) was carried out on different sample sizes to investigate the effects on product quality. Fick's second law model was used to determine the effective diffusivities of sunï dried chempedak slabs based on the drying rate versus moisture content plots. In addition, texture degradation and total color changes were investigated. The texture and color changes of dried chempedak were relatively significant $(\mathrm{p}<0.05)$ compared to fresh chempedak. There was an increase in dried fruit hardness and chewiness but a decrease in springiness and cohesiveness during drying.
\end{abstract}

Keyword: Chempedak; Color; Effective diffusivities; Sun drying; Texture 